\title{
IDENTIFICAÇÃO DE PROCESSOS DE CONHECIMENTO - ESTUDO MULTICASO EM APL DE CALÇADOS DE CAMPINA GRANDE
}

\section{IDENTIFICATION OF PROCESSES KNOWLEDGE - STUDY MULTICASES IN APL FOOTWEAR CAMPINA GRANDE}

\author{
Ricardo Jorge Araújo Silva ${ }^{1}$; Abraham Benzaquen Sicsú ${ }^{2}$; Antônio Pires Crisóstomo ${ }^{3}$ \\ ${ }^{1}$ Universidade Federal de Pernambuco - UFPE - Recife - Brasil \\ araujomail@gmail.com \\ ${ }^{2}$ Universidade Federal de Pernambuco - UFPE - Recife - Brasil \\ sicsu@,fundaj.gov.br \\ ${ }^{3}$ Universidade Federal de Pernambuco - UFPE - Recife - Brasil \\ antonio.crisostomo@univasf.edu.br
}

\begin{abstract}
Resumo
A construção do conhecimento nas empresas deixou de ser opção e passa a vigorar como importante função administrativa para as organizações que querem permanecer no competitivo mercado atual. Passado os modismos, o foco das atividades de conhecimento hoje é sua efetiva Gestão por meio de ações que prontamente estruturem modelos para Gestão para o Conhecimento. $O$ modelo de Diagnóstico da Gestão do Conhecimento (DGC) proposto por Bukowitz e Williams (2002) busca atuar nesta direção, o qual identifica pontos fracos na estruturação de um modelo de Gestão do Conhecimento empresarial propondo maneiras para melhorar a disseminação e utilização de conhecimento de forma tática e estratégica. Através de estudo multi-caso, o artigo apresenta os resultados de entrevistas semi-estruturadas feitas em nove importantes empresas localizadas no Arranjo Produtivo de Calçados em Campina Grande-PB e, baseado no modelo do DGC, mostra como se estrutura a utilização do conhecimento nas organizações e identifica também práticas associadas à geração de conhecimentos nas empresas através da experiência dos gestores. Os resultados sugerem que as empresas não têm uma estrutura ideal para aproveitamento do conhecimento em suas atividades e os poucos casos de práticas associadas ao aproveitamento do conhecimento focam suas ações de gestão em níveis táticos dirimindo atuações de nível estratégico, o que pode prejudicar a competitividade da organização.
\end{abstract}

Palavras-chave: Gestão do Conhecimento, processo, diagnóstico. 


\section{Introdução}

A disseminação de informações é um fator preponderante para os gestores das organizações visto, hoje, ser uma característica estratégica para a vantagem competitiva das empresas frente aos concorrentes e esta capacita às empresas criar valor frente aos seus clientes. Deste modo, não só a obtenção da informação, mas também a estrutura organizacional e o fluxo desta na empresa possibilitam uma vantagem competitiva essencial às organizações no mercado.

A criação de novas tecnologias de informação e comunicação é outro fator impulsionador das mudanças ambientas dos últimos anos. De acordo com Furlanetto et al (2005), a informação passou a ser conseguida de um modo mais fácil, sem as grandes limitações geográficas e temporais anteriores, o que proporcionou as empresas maior flexibilidade a agilidade de ações. Com isso, a possibilidade de que as empresas possam obter vantagens estratégicas pelo uso eficiente da informação proporcionou o início de vários estudos sobre a Gestão da Informação e do Conhecimento nas empresas. Não há novidade quando se fala em conhecimento nas organizações, o que mudou realmente foi a forma de vêlo como um grande potencial estratégico para os que puderem melhor utilizá-lo e disseminá-lo.

Embora as tecnologias de informação tenham possibilitado significativos avanços na competitividade das empresas, a posse dessa informação não garante ao seu possuidor uma vantagem estratégica sustentável se esta não for bem gerida, utilizada e disseminada em toda a organização. Deve-se também ressaltar a necessidade da empresa ter capacidade de absorção do conhecimento que é advindo externamente ou mesmo gerado dentro da própria empresa. De fato, alguns trabalhos como o de Sveiby (1998) tem mostrado que o principal ativo da empresa não se encontra em produtos tangíveis, mas sim em aspectos intangíveis, como sua imagem, relações com seus stakeholders, reputação da empresa, conceitos, modelos, sistemas administrativos e competência de seus funcionários.

Desta forma, vários autores têm contribuído grandemente para o estudo da Gestão do Conhecimento tornando-se assim um dos temas mais estudados na atualidade. As várias teorias e conceitos apresentados vêm desde a simples tipificação de conhecimento em ativos intangíveis (Sveiby, 1998) até ao tipo de processos de circulação de conhecimentos na empresa (Nonaka e Takeuchi, 1997). O grande número de autores que se preocuparam em definir formas de conhecimento, caracterizar os vários tipos de conhecimento, identificação deste na empresa e maneiras de utilizá-lo de forma estratégica tem possibilitado uma ampla bibliografia para o estudo da utilização do 
conhecimento na empresa. No entanto, autores recentes têm se preocupado não só na definição e localização do conhecimento, mas na aplicação desses estudos aos processos diários da empresa que, em última instância, é o que permite a organização ter um desempenho que possibilite a construção de uma competitividade presente e sustentabilidade futura.

Partindo deste pressuposto, o presente artigo apresenta um estudo realizado no APL de calçados na cidade de Campina Grande, Paraíba, no qual se mostram casos de nove empresas das onze mais bem sucedidas no setor, denominado grupo G11. O estudo avaliou fatores competitivos relacionados ao conhecimento como o proposto por Bukowitz e Williams (2002), o qual em seu livro Manual de Gestão do Conhecimento mostra uma ferramenta prática para aplicação de técnicas que visam estruturar a utilização, fluxo e criação do conhecimento nas empresas. Seus estudos são baseados em casos reais estudados pelas autoras que propõem um modelo de sete passos onde a empresa pode melhorar a sua estrutura de fluxo, obtenção e facilitação de uma criação eficiente do conhecimento. A aplicação da ferramenta procurou analisar até que ponto os casos estudados aplicam as práticas propostas pelas autoras e como essas práticas se revertem em melhorias de utilização dos ativos intangíveis da empresa proporcionando-lhe desenvolvimento. Os resultados do trabalho possibilitaram extrair destes alguns fatores considerados críticos para competitividade das empresas do setor baseados na gestão do conhecimento e elementos de gestão de inovação.

Para a consecução dos objetivos do trabalho, utilizou-se como metodologia a aplicação de questionário através de entrevistas realizadas com funcionários chaves das empresas. Foi utilizado o questionário Diagnóstico de Gestão do Conhecimento (DGC), que consta do livro das autoras. O artigo inicia-se com uma breve introdução do trabalho, seguido de alguns construtos teóricos utilizados no estudo. Segue uma contextualização do setor em que está inserida a empresa estudada, juntamente com informações dos casos estudados. Após isso, são mostrados os resultados obtidos e discussões da pesquisa e em seguida feitas às considerações finais.

\section{Fundamentação Teórica}

\subsection{Gestão do Conhecimento}

Em meio a crescente mudança e dificuldades que as organizações vêm enfrentando, a Gestão do Conhecimento tem mostrado excelentes fontes de trabalho antes esquecidos nas empresas. Fatores como Capital Intelectual, cultura organizacional, utilização de recursos intangíveis e de novas tecnologias, estão aumentando a capacidade da organização de trabalhar com a crescente complexidade 
do mercado tornando a gestão do conhecimento um importante fator estratégico para a sustentabilidade da organização.

Alguns autores como Hansen (1999) citam a existência da Gestão do Conhecimento desde muitos anos. Ele toma como exemplo as empresas familiares que transferem o conhecimento aos seus descendentes em atividades específicas, bem como o exemplo dos navegadores que ensinam os seus aprendizes, fazendo assim com que se evolua o conhecimento no desempenho de suas funções. Contudo, só a partir da década de 90 é que o conhecimento atingiu maiores proporções de desenvolvimento. Com o advento das tecnologias de informação, principalmente da internet, a disseminação do conhecimento entre organizações e indivíduos tem crescido grandemente.

Não é simples conceituar Gestão do Conhecimento, visto haver surgido variadas abordagens no decorrer do tempo cada uma com uma particularidade em relação ao seu tempo, desafios e circunstâncias. A prática de exploração do conhecimento nos diversos níveis organizacionais é uma das abordagens em que autores denotaram que incluir a obtenção de conhecimentos nos processos internos da organização consegue prover vantagens competitivas associadas ao conhecimento (Wiig, 1993).

As atividades que criam sinergia na organização como um todo é outra abordagem prescrita por autores que estudaram aspectos de gestão do conhecimento (Leonard-Barton, 1998). Para a autora há uma classificação preponderante de aptidões estratégicas nas organizações dividindo-os em três tipos distintos, a saber: Aptidões habilitadoras: Estas são necessárias a um funcionamento da empresa, mas não bastam para entrar em mercados onde inovação é característica típica para agregar valor competitivo em seus produtos; Aptidões Suplementares: Indicam uma adição de valor às aptidões estratégicas para competir com força no mercado, mas são facilmente imitadas por concorrentes e; Aptidões Estratégicas: São atividades essenciais baseadas na criação de Conhecimento e possibilitam às organizações a um conhecimento superior no mercado. São de difícil imitação e propícia a criar conhecimento patenteado. Leonard-Barton (1998) argumenta que as organizações devem focar suas atividades nas aptidões estratégica baseada na geração e difusão de conhecimento. Estas atividades compreendem a solução compartilhada de problemas para resolução de desafios atuais. Internamente na empresa a integração de atividades juntamente com implementação de novos métodos proporciona os meios necessários para utilizar conhecimentos necessários ao funcionamento atual. E externamente, a importação de conhecimentos seja especializado ou vindo do mercado é outra atividade que provê aptidão estratégica à organização. A mesma autora inovou em seus argumentos em relação à Wigg, ao incluir além dos processos internos, práticas de absorver conhecimento externamente a empresa não de forma convencional (como pesquisas de mercado) mas estudos relacionados a prospectar conhecimento 
em mercados altamente voláteis e dinâmicos, típicos de empresas que desejam inserir a inovação como agenda de desenvolvimento de suas atividades.

Como forma de acrescentar um novo elemento as abordagens estudadas até então, Barclay e Murray (1997) inserem a importante questão dos aspectos culturais na redefinição de processos. Os autores argumentam que a preocupação operacional é redefinir os processos para que possam convergir em atividades de conhecimento, e a cultura deve ser tratada de modo a definir aspectos como benefícios, preocupação na criação de lugares para incentivar diálogo, apoio da alta gerência com o fito de adotar uma cultura voltada à geração e disseminação de conhecimentos. Sem esgotar as possibilidades, Leif Edvinson e Malone (1997) mostraram um modelo de gestão do conhecimento subdividindo alguns recursos organizacionais e mostrando seus interrelacionamentos. O capital Humano, Capital Organizacional e Capital do Cliente são os recursos que as organizações possuem e as relações entre estes formam o que estes conceituaram como capital intelectual da empresa. Expandir a expertise do capital humano, encorajar a inovação na organização e exercitar a integridade para criar uma maior ligação com o capital intelectual são processos relacionados a atividade de Gestão do Conhecimento para os autores.

Nonaka e Takeuchi (1997), inovaram em relação às abordagens de gestão do conhecimento em seu trabalho que mostrou como empresas japonesas criavam a inovação de forma dinâmica através do que eles chamaram de conversão do conhecimento. Para eles, o conhecimento explícito e tácito poderia ser transformado um no outro por um modelo no qual mostraram sua funcionalidade por meio da espiral do conhecimento. A partir das práticas da combinação dos conhecimentos explícitos estes poderiam ser internalizados, transformando conhecimento explícito em tácito. A socialização do conhecimento tácito proporcionaria a externalização, que é a transformação do conhecimento tácito em explícito. Os autores mostram que a prática de Gestão do Conhecimento consiste em transformar as aptidões de maior competência, geralmente representada por conhecimentos tácitos especializados em conhecimentos explícitos.

Norteado por uma idéia semelhante, Karl Sveiby (1998) orientou sua abordagem na gestão da informação para aprendizagem organizacional. Esse autor insere a notação de Ativo intangível ao conhecimento que o dividiu de três modos na organização, quais sejam: 1) Competência do funcionário; 2) Estrutura Interna e 3) Estrutura externa. Baseado na idéia de que as organizações precisam atuar nas suas diversas competências sejam de funcionários ou estruturas, os processos organizacionais devem focar a transferência de conhecimento e fortalecimento das estruturas organizacionais. A notação posta pelo autor de Ativos intangíveis acrescentou as abordagens anteriores 
uma força maior a fim de enxergar o conhecimento e a maneira como este é gerido como um ativo a ser considerado nos negócios e atividades organizacionais.

Mais atualmente autores como Von Krogh et al (2001) inseriram uma nova dimensão à gestão do conhecimento onde argumentam que deve ser criada uma atmosfera propícia ao aprendizado e disseminação de informações. A criação desse contexto deve ser maior do que as intenções descritas nas missões em quadros da diretoria e repetidas inúmeras vezes dentro da organização. Deve ser baseada em relacionamentos robustos de modo a permitir uma nivelação de conhecimentos pelo fluxo de feedback e melhoria contínua de ações. A configuração de uma estratégia embasada no conhecimento depende de atividades que facilitem a criação do contexto necessário para gerir o conhecimento. Von Krogh et al (2001) enumera cinco capacitadores que auxiliam na criação de um contexto adequado. Inicialmente temos o capacitador denominado Instilar a visão do Conhecimento o qual denota que se devem integrar ações do conhecimento para enxergar o futuro e evitar a inércia perante as mudanças do ambiente. O segundo capacitador é a ação de gerenciar conversas, relacionado ao estímulo a participação e socialização de conhecimentos tácitos. $\mathrm{O}$ terceiro capacitador, Mobilizar ativistas do conhecimento, configura em colocar pessoas que possam inspirar outros na organização a continuar seus programas de conhecimento. É um motivador para os funcionários no meio às dificuldades que podem ocorrer na empresa. Criar um contexto adequado é o quarto ponto no qual o autor procurou denotar a idéia de criação de espaços para que o conhecimento acontecesse e não recriar as etapas para criar conhecimento. Por último temos o capacitador Globalizar o Conhecimento Local, o qual coaduna com o conceito de que o conhecimento deve ser disseminado e que o seu fluxo torna possível adquirir mais conhecimentos por meio da criação de relacionamentos baseados em cooperação com diversos atores, sejam clientes, fornecedores ou mesmo concorrentes. Ainda relacionado a este capacitador, o autor mostra que este deve ser gerido e controlado como forma de um processo estratégico.

Atualmente, vários autores têm dado definições usuais de Gestão do Conhecimento. Embora não possam afirmar que possuam uma definição final dela, todos geralmente falam de Gestão do Conhecimento como a utilização dos ativos intangíveis da empresa, ativos esses que estão relacionados a pessoas, processos, patentes, práticas e documentos, a fim de gerar valor e sustentabilidade para a organização, que é o caso de Bukowitz e Willams, que será posteriormente detalhado.

O quadro abaixo sintetiza algumas particularidades das principais abordagens conhecidas da gestão do conhecimento. A atividade de explorar conhecimentos internamente e o foco estratégico baseado em processos estão sempre presentes nos modelos. Esse é um fato compreensível, pois na grande maioria das organizações, com seus processos voltados ao objetivo inicial de eficiência 
produtiva, muitas atividades que apóiam o conhecimento como reuniões em equipes ou atividades de brainstorming podem ser relegadas a segundo plano. Pode-se observar também a evolução dos modelos onde nas abordagens iniciais a preocupação de criar conceitos para facilitar os esforços na sua gestão evoluindo a modelos mais preocupados com os processos gerenciais propriamente ditos como o de Von Krogh, que age nas condições capacitadoras e Bukowitz e Willams as quais denotam um processo gerencial para obter e utilizar o conhecimento nos processos empresariais.

A Configuração do Conhecimento Tácito e explícito será importante para o estudo, bem como o modelo gerencial da última abordagem mostrada no quadro, de forma que serão mais detalhados a seguir e servirão de modelos base para atingir os objetivos do artigo.

QUADRO 1 - Características dos Modelos de Gestão do Conhecimento

\begin{tabular}{|c|c|c|c|c|}
\hline Autor & Modelo & Ênfase & Foco Estratégico & Fatores de Sucesso \\
\hline$\overline{\text { Wigg (1993) }}$ & $\begin{array}{l}\text { Exploração do } \\
\text { Conhecimento } \\
\text { Organizacional }\end{array}$ & $\begin{array}{c}\text { Encontrar } \\
\text { conhecimentos } \\
\text { nos diversos } \\
\text { níveis } \\
\text { organizacionais }\end{array}$ & $\begin{array}{l}\text { Melhoria da Exploração das } \\
\text { práticas de obtenção de } \\
\text { Conhecimento. Atuação nos } \\
\text { processos }\end{array}$ & $\begin{array}{l}\text { Melhoria contínua, } \\
\text { Gestão da Qualidade, } \\
\text { Controle de processos. }\end{array}$ \\
\hline $\begin{array}{c}\text { Leonard- } \\
\text { Barton (1998) }\end{array}$ & Aptidão Estratégica & $\begin{array}{l}\text { Sinergia para } \\
\text { Criar melhorias } \\
\text { de atividades } \\
\text { em busca da } \\
\text { inovação }\end{array}$ & $\begin{array}{l}\text { Solução compartilhada de } \\
\text { problemas e acúmulo de } \\
\text { conhecimentos externos. Foco } \\
\text { na Inovação de produtos }\end{array}$ & $\begin{array}{c}\text { Trabalho em equipe, } \\
\text { Brainstorming, } \\
\text { Conexão com mercado, } \\
\text { Qualidade }\end{array}$ \\
\hline $\begin{array}{l}\text { Barclay e } \\
\text { Murray } \\
(1997)\end{array}$ & $\begin{array}{c}\text { Cultura do } \\
\text { Conhecimento }\end{array}$ & $\begin{array}{l}\text { Mudança } \\
\text { gradual da } \\
\text { cultura } \\
\text { organizacional }\end{array}$ & $\begin{array}{l}\text { Atuação nos processos. } \\
\text { Melhoria de estruturas internas } \\
\text { com mudança para uma cultura } \\
\text { de disseminação de } \\
\text { conhecimento }\end{array}$ & $\begin{array}{c}\text { Brainstorming, } \\
\text { Recursos Humanos, } \\
\text { competências, melhoria } \\
\text { contínua }\end{array}$ \\
\hline $\begin{array}{l}\text { Edvinson e } \\
\text { Mulone } \\
\text { (1997) }\end{array}$ & Capital Intelectual & $\begin{array}{l}\text { Relação entre } \\
\text { Capital } \\
\text { Humano, } \\
\text { organizacional e } \\
\text { do cliente. }\end{array}$ & $\begin{array}{l}\text { Expandir competência, } \\
\text { estimular inovação } \\
\text { organizacional, melhora } \\
\text { integração cliente-empresa } \\
\text { Inovação pela melhoria do } \\
\text { capital intelectual. }\end{array}$ & $\begin{array}{l}\text { Competências } \\
\text { humanas, Qualidade, } \\
\text { controle de processos, } \\
\text { qualidade de projeto, } \\
\text { pesquisa de mercado }\end{array}$ \\
\hline $\begin{array}{l}\text { Nonaka e } \\
\text { Takeuchi } \\
(1997)\end{array}$ & $\begin{array}{c}\text { Espiral do } \\
\text { Conhecimento }\end{array}$ & $\begin{array}{l}\text { Conversão do } \\
\text { conhecimento } \\
\text { tácito em } \\
\text { explícito }\end{array}$ & $\begin{array}{l}\text { Disseminar conhecimento } \\
\text { organizacional interno e } \\
\text { externo. Transformar aptidões } \\
\text { de maiores competências } \\
\text { inserindo-os em repositórios de } \\
\text { conhecimento }\end{array}$ & $\begin{array}{c}\text { Brainstorming, } \\
\text { Autonimia, } \\
\text { criatividade, controle } \\
\text { da qualidade, variedade } \\
\text { de requisitos. }\end{array}$ \\
\hline Sveiby (1998) & Ativos Intangíveis & $\begin{array}{l}\text { Aprendizagem } \\
\text { Organizacional }\end{array}$ & $\begin{array}{l}\text { Focar transferência de } \\
\text { conhecimento, Competência do } \\
\text { funcionário, melhoria das } \\
\text { estruturas internas e externas. }\end{array}$ & $\begin{array}{l}\text { Enxergar a Gestão do } \\
\text { conhecimento como } \\
\text { um ativo para os } \\
\text { negócios e organização }\end{array}$ \\
\hline $\begin{array}{l}\text { Von Krogh } \\
\text { (2001) }\end{array}$ & $\begin{array}{l}\text { Facilitar a Criação } \\
\text { do conhecimento }\end{array}$ & $\begin{array}{l}\text { Proporcionar } \\
\text { uma Atmosfera } \\
\text { propícia ao } \\
\text { aprendizado e } \\
\text { disseminação de } \\
\text { informações }\end{array}$ & $\begin{array}{c}\text { Agir em condições } \\
\text { capacitadoras para facilitar a } \\
\text { disseminação do conhecimento } \\
\text { e possibilitar inovações }\end{array}$ & $\begin{array}{l}\text { Recursos humanos, } \\
\text { Motivação de } \\
\text { funcionários, } \\
\text { Treinamentos, } \\
\text { Qualidade, trabalho em } \\
\text { equipe, Brainstorming }\end{array}$ \\
\hline
\end{tabular}




\begin{tabular}{|c|c|c|c|c|}
\hline $\begin{array}{l}\text { Bukowitz e } \\
\text { Williams } \\
(2002)\end{array}$ & $\begin{array}{l}\text { Manual de Gestão } \\
\text { do Conhecimento }\end{array}$ & $\begin{array}{c}\text { Atuar na } \\
\text { geração, } \\
\text { obtenção e } \\
\text { manutenção do } \\
\text { conhecimento } \\
\text { na organização }\end{array}$ & $\begin{array}{c}\text { Diagnosticar sete áreas } \\
\text { principais para Gestão do } \\
\text { Conhecimento atuando nas } \\
\text { áreas deficitárias }\end{array}$ & $\begin{array}{l}\text { Comunidades de } \\
\text { prática, trabalho em } \\
\text { grupo, controle da } \\
\text { qualidade de } \\
\text { informações, } \\
\text { Brainstorming }\end{array}$ \\
\hline
\end{tabular}

\subsection{O Conhecimento na Organização}

Para Nonaka e Takeuchi (1997) o conhecimento pode ser definido como uma "crença verdadeira e justificada" e os mesmos diferenciam Conhecimento da Informação onde o primeiro se relaciona à ação e tem relação às crenças e compromissos. Para os autores, dentro da organização, o Conhecimento pode ser disseminado e introduzido em produtos, processos, sistemas e outros tipos que impactam diretamente na estrutura organizacional da empresa.

Duas dimensões do conhecimento são subdivididas dentro das estruturas e sistemas da empresa, a saber: Conhecimento Tácito e Conhecimento Explícito. Apesar de definições díspares são elementos mutuamente complementares para o entendimento da dinâmica do conhecimento na organização.

Segundo Polanyi (1967), o conhecimento expresso em palavras e números representa apenas a ponta do iceberg do conjunto de conhecimentos na organização. Em seus estudos o autor denotou que o conhecimento tácito é altamente pessoal e de difícil formalização, é profundamente enraizado nas ações e experiências individuais, como emoções, valores ou ideais, o que dificulta sua transmissão e compartilhamento e, portanto, sua conversão em informação. A base do conhecimento dos principais especialistas de mercado é alicerçada em elementos tácitos provindas de experiências, metodologias. No conhecimento explícito os indivíduos são capazes de expressá-lo e torná-lo acessível aos que dele necessitam facilmente. Alguns repositórios de conhecimento também possuem conhecimento explícito como linguagens, banco de dados, comunicações visuais, sonoras, corporais, entre outros.

Assevera-se que a vantagem estratégica da empresa está no fato dela saber convergir o conhecimento tácito dos funcionários, e colaboradores externos em conhecimento explícito, e que este possa ser internalizado por outros funcionários da empresa ou que se possam criar repositórios deste conhecimento acessíveis na organização. As práticas e processos utilizados na organização são fatores essenciais para apoiar a conversão do conhecimento na organização. De modo mais elementar, afirmase que é a Gestão do Conhecimento que pode agregar valor nos produtos e serviços da empresa para lhe auferir vantagens competitivas. Com foco nessa gestão, a formulação de um diagnóstico para das ações de conhecimento na empresa é o passo inicial para prover uma gestão eficiente. Um plano de ações 
corretivas nos principais pontos fracos e acompanhamento destes completam o ciclo para melhoria das ações baseadas no conhecimento na empresa.

\subsection{Práticas para gestão de ativos intelectuais}

Algumas ferramentas de gestão do conhecimento são direcionadas a aplicações práticas de métodos e técnicas para o aprimoramento dos processos de utilização do conhecimento nas empresas. Essas ferramentas são as ações de aprendizado que relacionamos com a aquisição de conhecimentos e adoção de formatos organizacionais que possibilitem uma estruturação dos meios e processos por meio do qual a empresa utiliza e por onde circula o conhecimento. Dentre estas ferramentas destacamos o modelo de sete passos contidos no Manuel de Gestão do Conhecimento.

Manual de Gestão do Conhecimento: Em uma economia que atribui crescentemente a vantagem competitiva à gestão dos ativos intangíveis colocando em outro plano a posse do capital tangível, torna-se imprescindível uma abordagem inovadora para compreender e gerir com qualidade o conhecimento dentro da organização. Para isto, a contribuição de Bukowitz e Williams (2002) exprime sete passos básicos para este fim, os quais envolvem a organização como um todo. Esses passos são explicitados em seu livro Manual de Gestão do Conhecimento, sendo este um excelente guia para aplicação prática de ferramentas e técnicas que possibilitam a criação de valor para a empresa.

Apesar de o livro identificar passos que auxiliam a formação de melhores estruturas organizacionais voltadas a criação de conhecimentos, o mesmo está longe de ser identificado como um "livro de receitas" para as empresas. Da mesma forma ele não deve ser considerado como a resposta para as organizações que desejam aplicar formas de gestão de ativos intelectuais.

O Manual de Gestão do Conhecimento mapeia alguns caminhos que já foram utilizados por outras empresas que produziram benefícios preeminentes na criação de valor. O livro é orientado pela sua aplicabilidade, onde através de técnicas didáticas proposta pelas autoras, as organizações podem fazer ligações entre os vários conceitos de Gestão do Conhecimento e ações específicas que são utilizadas na empresa ou que possam vir a serem implementadas. Os sete passos que norteiam o Manual de Gestão do Conhecimento são os seguintes:

1. Obter: A obtenção de informação e conhecimento, como o primeiro passo do processo de gestão do conhecimento é lugar comum na maioria das organizações, no entanto esta realidade vem tomando outro formato, já que a utilização de técnicas e tecnologias de informação tem sido uma 
ferramenta utilizada pelas organizações para potencializar seus ativos intangíveis, fazendo-os diferenciais competitivos.

2. Utilizar: É de grande valia a obtenção de informações e a busca pelo conhecimento, mas terá nenhuma utilidade se não for bem aplicado, assim mostra as autoras. A boa (ou a má) utilização do conhecimento atinge diretamente o cliente, de maneira que esta fase está totalmente voltada para ele, na busca de sua satisfação.

3. Aprender: Agregar valor à informação é basicamente o gargalo que as organizações enfrentam atualmente, já que o processo de obtenção e utilização da informação e do conhecimento é mecânico. "Isso ocorre porque é mais difícil de estabelecer ligações entre aprender e criar valor do que obter e utilizar a informação".

O processo de aprendizagem caminha em paralelo com a contribuição, pois ela é o catalisador da criação e aplicação de idéias novas, valendo salientar que este processo é mediato, cíclico e interminável.

4. Contribuir: A transferência do conhecimento tácito para o conhecimento explícito é o norte da gestão do conhecimento, transformando as pessoas como parte fundamental das organizações. No entanto, o processo de inspirar os funcionários à contribuição é um tanto quanto limitado para as organizações, já que este exige um alto empenho financeiro. Portanto, as organizações precisam estar atentas à qualidade da geração de idéias inovadoras e úteis e a capacidade de utilização destas idéias por parte de seus funcionários.

O processo de contribuição apresenta grandes empecilhos, já que este é um passo que depende única e exclusivamente dos colaboradores da organização. Mesmo que a organização ofereça ambientes totalmente favoráveis e atinja com êxito os imperativos propostos por modelos e práticas, este passo é concretizado apenas com as ações individuais.

5. Avaliar: Voltado para o lado estratégico, o processo de avaliar responde às mudanças do ambiente macroeconômico e depende: da "direção estratégica, variações na velocidade e intensidade das respostas organizacionais ao mercado e mudanças no nível de distribuição de recursos”. Sendo assim, este passo está a cargo da liderança organizacional, através de um planejamento estratégico que é contínuo e influencia toda a organização.

6. Construir e Manter: Este passo está voltado para o futuro, de maneira que o gerenciamento do conhecimento viabilize uma competitividade estável à organização. Para os autores, o desenvolvimento do conhecimento deve-se dividir em três partes principais: construir, manter e descartar. Sendo o construir relacionado com o desenvolvimento do conhecimento, o manter 
relacionado com a proteção e o cultivo do conhecimento, já o descartar é rejeitar o conhecimento que não tem utilidade presente ou futura.

7. Descartar: Costumeiramente, as organizações retêm seus conhecimentos não rentáveis, e isto é um erro que incorpora custos e perda de tempo à organização. A otimização da utilização de conhecimento reduz tempo e custos descartáveis.

Como já mencionado anteriormente, o trabalho terá seu foco principal no modelo composto por esses sete passos do modelo das autoras e a maneira como conduzida a pesquisa será mostrado nos procedimentos metodológicos utilizados. Os construtos teóricos também mostrados na fundamentação será base para entendimento de alguns questionamentos, de ordem qualitativa, feitos às empresas.

\section{Procedimentos Metodológicos}

A partir do modelo como proposto por Bukowitz e Williams (2002) na identificação das práticas gestão do conhecimento do Arranjo Produtivo das empresas de calçados de Campina Grande, a metodologia utilizada centrou-se na identificação de atividades geradoras do Conhecimento que são utilizadas de forma estratégica pelas empresas pesquisadas.

A pesquisa foi conduzida em nove companhias de calçados que compõe o grupo das onze maiores empresas na cidade. O método utilizado foi o estudo de caso múltiplo tipo explanatório, pois este foi considerado o mais adequado para identificação dos processos de conhecimento, no qual foi suposto inicialmente que esse fenômeno seria comum as empresas estudadas, mesmo que em graus diferentes, sendo para isso necessário observar as perspectivas dos indivíduos nos distintos contextos das empresas.

Em relação ao número de funcionários, podemos classificar os casos estudados na seguinte perspectiva:

Figura 1 - Distribuição das empresas por número funcionários 


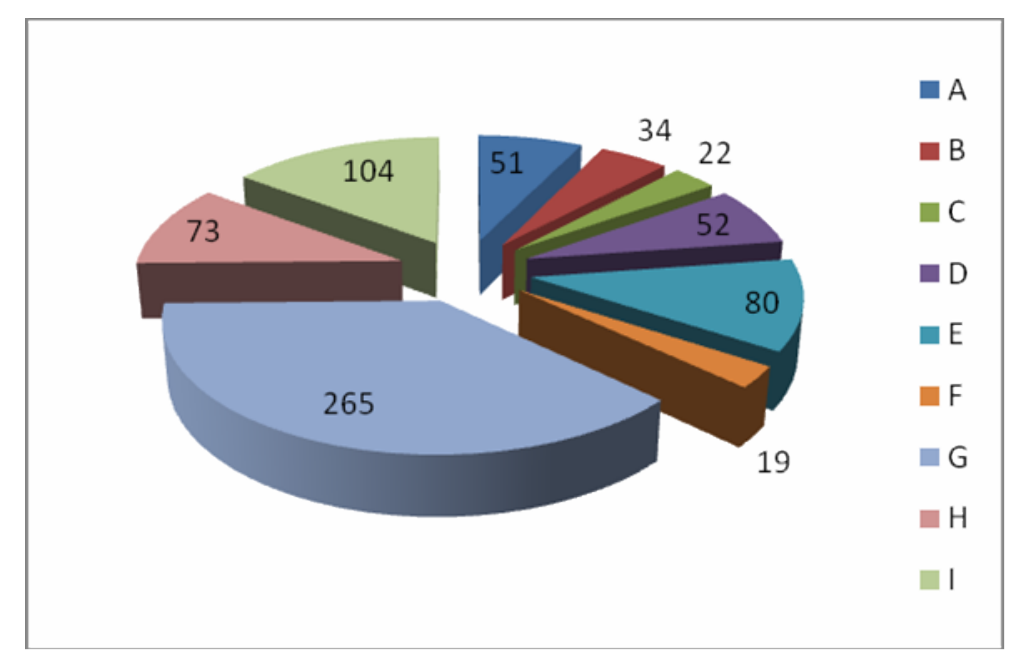

Fonte: Pesquisa de Campo

Considerando o estatuto da micro e pequena empresa os casos se identificam da seguinte maneira:

Quadro 2: Distribuição das empresas quanto ao número de funcionários

\begin{tabular}{cc}
\hline $\mathbf{N}^{\mathbf{0}}$ de funcionários & Número de empresas estudadas pelo critério funcionários \\
\hline $0-19$ (micro) & 1 empresa \\
$20-99$ (pequena) & 6 empresas \\
$100-$ acima (média) & 2 empresa \\
Total & 9 empresas \\
\hline
\end{tabular}

Fonte: Pesquisa de Campo

A coleta de dados foi feita através de entrevistas semi-estruturadas, com aplicação de um questionário adaptado do modelo proposto por Bukowitz e Williams (2002), denominado Diagnóstico da Gestão do Conhecimento, e feitas algumas perguntas de caráter qualitativo. As observações nãoparticipantes e análise de documentos consolidados sobre o setor foram outros métodos utilizados o que para Yin (2001) são meios eficazes para coleta de informações de cunho qualitativo. Uma representação gráfica do modelo é descrita na figura 2 de modo que se verifica que dos sete passos descrito pelas autoras, os quatro primeiros são de caráter tático que são demandadas por meio de oportunidades externas. Os outros são processos estratégicos desencadeados por mudanças macroambientais.

Figura 2: Processo de gestão do Conhecimento 
Tàtico

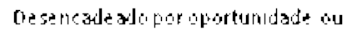

derlanda deriga pelatiercalo

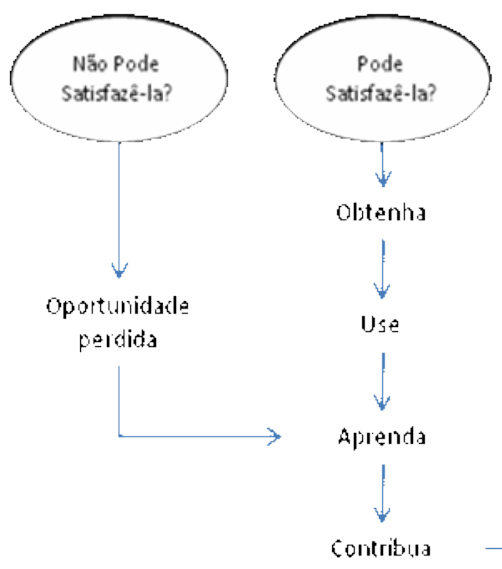

Estratégico

Drsencadeadoper mudarça no

N.lacroanibients

Conhecimento

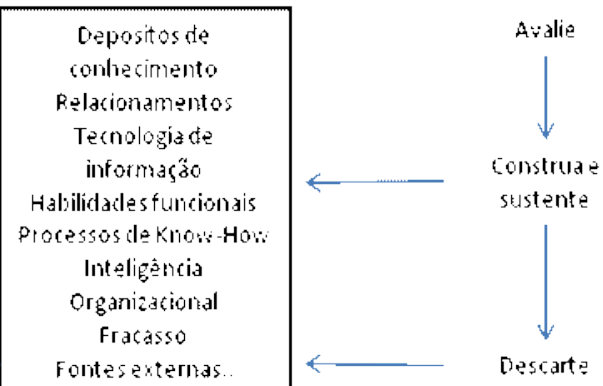

Fonte: Bukowitz e Willims, ( 2002)

O questionário proposto pelas autoras em seu trabalho foi adaptado às circunstâncias das empresas estudadas, mas foram tabuladas da maneira como proposta por estas em seu modelo. Divididas em sete seções, cada uma representando um passo no processo de gestão, este era composto de várias afirmações relacionadas aquele processo específico. Para afirmação sobre cada um dos passos, o respondente marcava se havia uma correlação Forte, Moderada ou Fraca. Encerradas todas as afirmativas da seção, calculava-se a pontuação geral daquela seção da seguinte forma:

- O número de afirmações fortes multiplicado por três;

- O número de afirmações moderadas multiplicado por dois;

- O número de afirmações fracas multiplicadas por um;

- Soma-se o total multiplicado de todas as afirmações;

- Essa pontuação total dividia-se por Sessenta, a qual representa a pontuação total possível;

- O número residual denota a pontuação percentual deste processo.

Por meio desse percentual dos processos, foi avaliado cada um dos casos estudados e a feita análise posterior do desempenho geral das empresas. Os dados coletados para a análise foram obtidos através de entrevistas feitas aos proprietários, ou funcionários com cargos de gerência nas empresas. Os resultados foram tabulados e analisados por parâmetros de média, identificando as práticas mais 
utilizadas na empresa e os pontos a melhorar. Por meio dos questionamentos de ordem qualitativa alguns fatores considerados críticos nas empresas forma apontados baseadas nas suas atividades de gestão do conhecimento.

\subsection{A indústria de Calçados nacional}

O Brasil é composto de cerca de 4000 empresas de calçados sendo que sua maioria é de pequenas empresas. $\mathrm{O}$ setor caracteriza-se por ser uma atividade exercida por capital nacional e as empresas originando-se a partir de formas de produção artesanal, onde os seus empreendedores caracterizam-se pelo domínio de técnicas de produção, com uma grande capacidade de trabalho. As empresas são em sua maioria familiar e dirigidas por membros da família, com o sistema de aprendizado e direção das empresas sendo passado de pai para filho.

A indústria brasileira hoje está entre as maiores do mundo junto com a da China e da Itália. Esta posição de destaque foi conquistada a partir do final da década 60 e início dos anos 70, quando a indústria iniciou o processo de conquista do mercado externo, ocupando um espaço no mercado em que, os produtores italianos e espanhóis, em crise, não conseguiam atender plenamente, qual seja, o de preços mais baixos. O setor calçadista brasileiro foi também um dos primeiros a exportar produtos manufaturados.

A origem do complexo coureiro-calçadista brasileiro remonta a meados do século XIX, quando imigrantes europeus implementaram a atividade de curtume do couro (COSTA e FLIGESNSPAN, 1997), visando a fabricação de selas para a montaria e sandálias, possibilitadas em função da existência anterior de pecuária de corte nessas regiões.

Essas unidades produtivas eram caracterizadas por sua microdimensão, pela forma de produção rudimentar e pelos laços familiares. $\mathrm{O}$ nascedouro da indústria calçadista foi possibilitado pelo aproveitamento de subprodutos do couro. De um início imbricado, as indústrias de couro e calçadista passam ao longo do tempo a seguir trajetórias próprias gerando um desmembramento crescente de suas atividades.

As empresas nacionais de curtumes localizam-se majoritariamente no Rio Grande do Sul e em São Paulo, embora outro pólo, o de Minas Gerias, vem se destacando em função da relocalização de rebanhos e frigoríficos. Outra característica marcante do setor calçadista brasileiro é a existência de empresas com diferentes níveis de capacitação e eficiência de mercado, grande diversidade de segmentos, intensidade na utilização de mão-de-obra, relativa fusão tecnológica do processo produtivo e alta pulverização em nível mundial. O principal fator determinante da competitividade dessa indústria 
é a força de trabalho, sobretudo para os segmentos de consumo popular e de média qualidade. Na faixa de maior valor agregado, entretanto, fatores como a classe da matéria-prima, design, e marca própria possuem maior relevância, apesar dos custos de mão-de-obra serem, também, significativos.

No Brasil há dois principais clusters produtores de calçados: Franca, especializada em calçados masculinos e o Vale dos Sinos, especializado em calçados femininos. A oferta de calçados no Brasil pode ser dividida a partir do porte das empresas e sua forma de atuação. As grandes empresas atuam principalmente no mercado interno, com forte presença na produção de tênis, com tecnologia mais sofisticada e maiores despesas de marketing. As médias empresas, especializadas em sapatos de couro (natural) tem atuação voltada principalmente para o mercado externo. As micro e pequenas empresas utilizam-se de processos artesanais e estão mais sujeitas as variações da economia.

Vários estados iniciaram o processo de fabricação de calçados em escala industrial no Brasil a partir da segunda metade do século passado e um desses estados foi a Paraíba. Graças a sua vocação "coureira" e de algodão, tais produtos conseguiram se inserir em mercados brasileiros e nas economias mais avançadas do mundo. No estado da Paraíba as cidades que se destacam na produção de calçados são as de João Pessoa, Campina Grande e Patos. Na primeira predominam as grandes empresas, geralmente vindas através de incentivos fiscais do governo. Nas outras duas cidades predominam as pequenas e micro empresas, destas duas sendo a cidade de Campina Grande a que possui um maior número de empresas.

\subsection{A formação do APL de calçados em Campina Grande}

A vocação coureira e a posição geográfica privilegiada entre o sertão e a cidade do Recife-PE, fizeram com que Campina Grande se constituísse em um dos principais centros produtores de calçados do Brasil e o principal da região Nordeste.

O surgimento da atividade coureira de Campina Grande iniciou-se no ano de 1923 com a criação de Curtumes na cidade, fruto da iniciativa pioneira da família Motta, quando a cidade possuía cerca de 4000 habitantes (ALBUQUERQUE, 1998). Sua produção destinava-se inicialmente à confecção de selas, arreios e rédeas para montarias, muito utilizadas no meio rural. A existência de um grande rebanho bovino, ovino e caprino na região deu origem a indústria do couro e esta por sua vez, criou as pré-condições para a fabricação de calçados e afins (subprodutos do couro). A vocação histórica para trabalhar com o couro e subseqüentemente com calçados e afins aparece como explicação predominante do desenvolvimento do arranjo produtivo coureiro-calçadista de Campina Grande. A produção do couro de Campina Grande teve seu período de apogeu entre 1940-1954, 
sobretudo na Segunda Grande Guerra, quando exportavam seus produtos. Nas décadas de 60 e 70 a indústria coureira entra em processo de declínio reduzindo o número de curtumes à metade, fato atribuído principalmente ao acirramento da concorrência com o Rio Grande do Sul. É também a partir deste período que as atividades de produção de calçados iniciam seu crescimento.

Apesar do seu declino nos anos 70, Campina Grande ainda mostrou-se ser de relevada importância para o setor. No entanto, a sua importância veio a ser diminuída a partir dos anos 80 , fato ocorrido principalmente devido às dificuldades de funcionamento dos curtumes instalados na região. Hoje têm-se como uma herança histórica de produção de calçados de Campina Grande um vasto contingente de sapateiros e produtores informais, onde muitos adquiriram experiência na produção de calçados passando-se, de forma geral, em processo de difusão familiar de conhecimentos.

Atualmente, o arranjo coureiro-calçadista de Campina Grande é composto fundamentalmente por produtores locais de micro, pequeno a médio porte de calçados e artefatos de couro ou de material sintético, sendo grande parte das empresas é de estrutura familiar. Ressalta-se, ainda, a entrada de empresas de fora do arranjo, mais especificamente das regiões Sudeste e Sul, a partir da década de 1980.

De fato, na década de 80 , duas grandes empresas do sul se instalaram no município, uma produtora nacional de sandálias de material sintético originária do Estado de São Paulo, e uma das maiores produtoras nacionais de calçados femininos, da região Sul. Esta última se instalou no município em 1983, contudo, em 1997 fechou a fábrica de Campina Grande, de acordo com informações, por não terem sido renovados os incentivos fiscais oferecidos.

O que se observa da entrada destas empresas foi que poucas relações intra-arranjo foram promovidas por elas. Na verdade, a dinâmica do arranjo não foi alterada de forma substantiva, mas criaram alguns fatores diferenciais para o mesmo, entre eles a prática de salários maiores do que a média local e a capacitação de maior nível (PINHANEZ, 1998).

O arranjo coureiro-calçadista de Campina Grande até meados da década de 1990 apresentava um quadro de desenvolvimento econômico promissor, com reflexos no município e na região (Pinhanez, 1998). Sua importância pode ser reconhecida a partir de alguns fatores:

a) A articulação de vários organismos públicos e privados para estimular seu desenvolvimento através de estudos e diagnósticos e da elaboração e implantação de alguns programas ou projetos voltados para o setor; 
b) A criação desde a década de 1970 de capacitação científica e tecnológica na universidade federal para a formação de graduados e especialistas;

c) A posterior criação de um centro tecnológico específico para couro e calçados, único da região Nordeste;

d) O pioneirismo na atração, através de incentivos, de grandes empresas de outras regiões do país, incluindo fornecedoras de insumos para a indústria calçadista.

Segundo dados apresentados por Furlanetto e Silva (2006), somente em Campina Grande existiam, no ano de 2005, algo em torno de 42 empresas atuando em vários segmentos do mercado de calçados e produtos afins, com uma variedade de produtos que podem ser agrupados em três segmentos distintos: calçados e artefatos de couro; calçados de materiais sintéticos e; equipamento de proteção individual de couro. Deste universo, cerca de 31 empresas produzem exclusivamente calçados, tanto de couro, como sintéticos. Além destes existe um contingente de cerca de 190 produtores informais no Arranjo de Campina Grande.

Existe ainda no arranjo de Campina Grande o segmento de empresas fornecedoras de insumos e componentes para a produção de calçados. Trata-se de um segmento relativamente pequeno formado por 7 empresas gerando cerca de 140 empregos e produzindo colas, adesivos, solados e uma matrizaria. Segundo trabalhos (FURLANETTO e SILVA, 2005), este é um dos grandes "gargalos" do setor e que o torna ainda muito dependente de outros centros produtores do país.

Há ainda no setor importantes instituições que amparam as atividades de desenvolvimento e apoio à inovação. Dentre as mais importantes instituições merecem destaque o SENAI, o SEBRAE e a Universidade Federal de Campina Grande - UFCG que mantém, em parceria com o SENAI, um curso de Engenharia de Produção com uma de suas áreas de atuação voltada a projetos para couro e calçados.

É importante mencionar, ainda, que devido à própria organização dos empresários locais, é em Campina Grande que se encontra o Sindicato dos Calçadistas e a própria Federação das Indústrias do Estado da Paraíba, o que acaba dando maior força política ao arranjo local. Trata-se, portanto, de um verdadeiro "arranjo produtivo local de couro e calçados", conforme classificação feita em estudos por Cassiolato e Szapiro, (2002).

Para o classificarem como arranjo produtivo local os autores o fizeram com base na presença das seguintes características: governança por "redes" de micro e pequenas empresas, isto é, sem a presença de relações hierarquizadas entre agentes assimétricos; produção voltada para o mercado local, potencializando a interação usuário-produtor e gerando oportunidades de aprendizado e capacitação 
para inovação e; média territorialidade, já que as capacitações necessárias ao processo inovativo encontram-se "enraizadas" localmente, facilitando processo de aprendizado local.

\section{Resultados}

Nos resultados foram observadas as características do modelo proposto para cada um dos casos estudados e em seguida feito algumas considerações analíticas pelo cruzamento de dados e buscados através das informações qualitativas aplicadas nas entrevistas. De modo geral, a percentagem da pontuação para cada processo é identificado abaixo:

Tabela 1: Processos de conhecimento nos casos estudados

\begin{tabular}{|c|c|c|c|c|c|c|c|c|c|}
\hline Empresa & Obter & Utilizar & Aprender & Contribuir & Avaliar & Construir & Descartar & $\begin{array}{c}\text { Desemp. } \\
\text { Forte }\end{array}$ & $\begin{array}{c}\text { Desemp. } \\
\text { Fraco } \\
\end{array}$ \\
\hline A & $66 \%$ & $85 \%$ & $63 \%$ & $73 \%$ & $50 \%$ & $76 \%$ & $60 \%$ & $\begin{array}{l}\text { Utilizar } \\
(85 \%)\end{array}$ & $\begin{array}{c}\text { Avaliar } \\
(50 \%)\end{array}$ \\
\hline B & $63 \%$ & $58 \%$ & $75 \%$ & $57 \%$ & $47 \%$ & $63 \%$ & $53 \%$ & $\begin{array}{c}\text { Aprender } \\
(75 \%)\end{array}$ & $\begin{array}{c}\text { Avaliar } \\
(47 \%)\end{array}$ \\
\hline $\mathrm{C}$ & $70 \%$ & $70 \%$ & $75 \%$ & $63 \%$ & $75 \%$ & $70 \%$ & $81 \%$ & $\begin{array}{c}\text { Descartar } \\
(81 \%)\end{array}$ & $\begin{array}{c}\text { Contribuir } \\
(63 \%)\end{array}$ \\
\hline $\mathrm{D}$ & $68 \%$ & $72 \%$ & $73 \%$ & $79 \%$ & $60 \%$ & $73 \%$ & $67 \%$ & $\begin{array}{c}\text { Contribuir } \\
(79 \%)\end{array}$ & $\begin{array}{c}\text { Avaliar } \\
(60 \%)\end{array}$ \\
\hline $\mathrm{E}$ & $52 \%$ & $41 \%$ & $40 \%$ & $52 \%$ & $42 \%$ & $50 \%$ & $61 \%$ & $\begin{array}{c}\text { Descartar } \\
(61 \%)\end{array}$ & $\begin{array}{c}\text { Aprender } \\
(40 \%)\end{array}$ \\
\hline $\mathrm{F}$ & $56 \%$ & $52 \%$ & $72 \%$ & $49 \%$ & $41 \%$ & $59 \%$ & $59 \%$ & $\begin{array}{c}\text { Aprender } \\
(72 \%)\end{array}$ & $\begin{array}{c}\text { Avaliar } \\
(41 \%)\end{array}$ \\
\hline G & $62 \%$ & $64 \%$ & $43 \%$ & $52 \%$ & $56 \%$ & $43 \%$ & $54 \%$ & $\begin{array}{c}\text { Utilizar } \\
(64 \%)\end{array}$ & $\begin{array}{c}\text { Aprender e } \\
\text { construir } \\
(43 \%)\end{array}$ \\
\hline $\mathrm{H}$ & $67 \%$ & $68 \%$ & $65 \%$ & $60 \%$ & $47 \%$ & $63 \%$ & $47 \%$ & $\begin{array}{c}\text { Utilizar } \\
(68 \%)\end{array}$ & $\begin{array}{c}\text { Avaliar e } \\
\text { descartar } \\
(47 \%)\end{array}$ \\
\hline I & $43 \%$ & $48 \%$ & $56 \%$ & $39 \%$ & $43 \%$ & $47 \%$ & $41 \%$ & $\begin{array}{c}\text { Aprender } \\
(56 \%)\end{array}$ & $\begin{array}{c}\text { Contribuir } \\
(39 \%)\end{array}$ \\
\hline
\end{tabular}

Fonte: Pesquisa de Campo

Na tabela 1 é observado que, para cada empresa, foi apresentado a pontuação atingida em cada processo, bem como o desempenho de maior e menor destaque. O gráfico das médias correspondentes 
nos mostra que, para as empresas como um todo, os processos de Aprender $(62,44 \%)$ e Utilizar (62\%) são os mais observáveis.

Figura 3: Média do desempenho

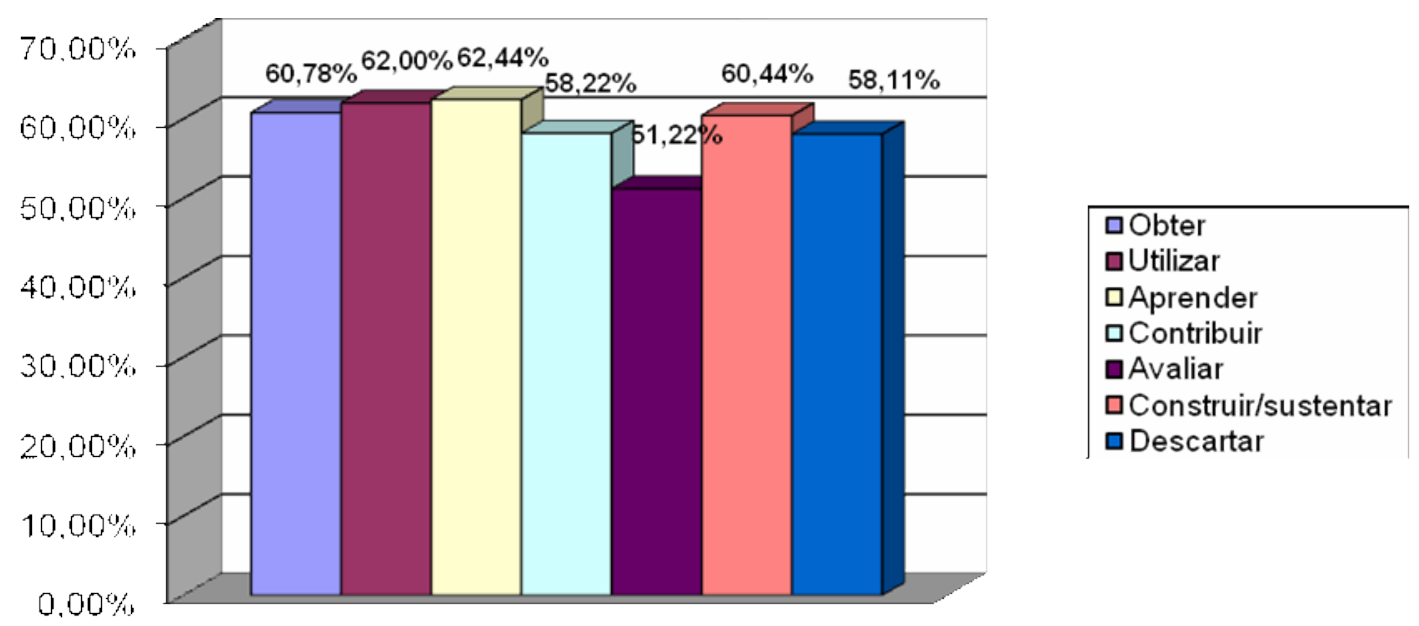

Fonte: Pesquisa de Campo

Utilizando-se de funções do programa Microsoft Excel ${ }^{\mathrm{TM}}$ de máximo, mínimo e da mediana, a tabela seguinte denota os processos de maior e menor desempenho, bem como o de desempenho moderado.

Tabela 2: Medidas de desempenho geral

\begin{tabular}{ccc}
\hline Melhor desempenho & $62,44 \%$ & Aprender \\
\hline Desempenho moderado & $60,44 \%$ & Construir/sustentar \\
Desempenho fraco & $51,22 \%$ & Avaliar \\
\hline
\end{tabular}

Fonte: Pesquisa de Campo

De modo sucinto, foi identificado nas empresas uma dificuldade tática na atividade de Contribuição do conhecimento. A falha na disseminação do conhecimento é fator crítico para essas empresas, principalmente se considerado que, embora haja uma boa percentagem no aprendizado, se este não for bem disseminado, o caráter competitivo da conversão de conhecimentos tácitos em explícitos prejudica a intenção de utilizar o conhecimento de forma estratégica.

Como denotado no modelo, os três últimos passos são considerados de nível estratégico, induzidos pelas mudanças ambientais tecnológicas, da concorrência entre outros. A vulnerabilidade é maior nesses processos, visto que possuem índices de menor avaliação (Avaliar ,51,22\%; Descartar, 
$58,11 \%$ ). Visto esse processo ser intrinsecamente relacionado à estratégia empresarial e norteado pela alta administração da organização, os índices fracos deste mostram que não há um foco nas empresas direcionado a utilização do conhecimento como fator competitivo estratégico. Sem este direcionamento, as atividades geridas pelo conhecimento se resumem as operações diárias na produção e modelagem de calçados, fato este corroborado por observação direta nas visitas in loco e nos questionamentos durante as entrevistas com proprietários.

A troca de conhecimentos com fornecedores locais é dificultada pela ausência de empresas fornecedoras de destaque no Arranjo. Pesquisa realizada por Furlanetto e Silva (2006) mostra que há poucas empresas no arranjo e mesmo dentre estas, grande parte do seu mercado consumidor está fora do estado. As empresas locais compram a maioria de seus materiais de empresas fora do estado o que dificulta a intenção de troca de conhecimentos entre eles.

Nas entrevistas foi questionado aos proprietários de que forma acontecem os diversos processos na percepção destes, procurando neste ponto possíveis exemplos ou experiências consideradas de sucesso. Sintetizando as respostas dos empresários, denotamos o seguinte:

OBTER - O processo de obter conhecimentos é feito geralmente por meio de revistas especializadas, feiras de calçados nacionais e internacionais, e em alguns casos através de interações com fornecedores e clientes. Em um dos casos observados uma empresa fabricante de sandálias femininas no arranjo (Nomeado como empresa C) merece destaque o fato de que esta se utiliza constantemente de informações e serviços de instituições do setor. A empresa em questão alegou que procura obter o máximo dos serviços que esta utiliza é o laboratório do Senai - CTCC, sendo este credenciado pelo INMETRO onde testa seus produtos e recebe um tipo de selo de qualidade (Não certificação de qualidade).

Também utiliza o máximo dos serviços desta instituição para realizar treinamentos com seus funcionários, sendo o único caso observado que se mostrou disposto a permitir que seus funcionários pudessem fazer cursos para o aperfeiçoamento da linha de produção. Quando indagado se essas ações melhoravam a competitividade de sua empresa este respondeu de modo afirmativo. Um exemplo citado por ele próprio foi o de suas vendas durante os meses de janeiro. Este é um período de sazonalidade de vendas para a maioria das empresas do setor, onde muitos deles, pelo pequeno volume de produção, vendem pouco ou mesmo dão férias coletivas a toda a sua linha de produção. $O$ mesmo afirmou que durante este mês, sua empresa produziu calçados femininos de boa qualidade e valor agregado e $80 \%$ de sua produção neste mês foi para países Europeus, destacando países como Alemanha e Itália.

Obviamente este fato depende muito das oscilações econômicas, o qual afirmou que não pôde utilizar essa tática nos meses iniciais deste ano (2009), visto a crise econômica ter ocorrido pouco 
tempo antes. No entanto, também disse que contatos posteriores com seus compradores europeus mostraram que há boa intenção de permanecer as compras nos meses iniciais dos anos subseqüentes.

UTILIZAR - A utilização dos conhecimentos advindos interna ou externamente na empresa é focada diretamente em sua linha de produção e sempre relacionada à produção. Fator sempre citado foi a utilização dos atuais encontros de design feitos por consórcio de fornecedores de materiais de calçados em nível nacional. Trimestralmente essa instituição nacional promove encontros sobre design e tendências da estação posterior onde todos os entrevistados são convidados. Esses encontros além de permear o processo de obter conhecimentos classificam também como um processo de utilização destas informações advindas dos fornecedores.

APRENDER - O processo de aprender como mostrado na percepção dos empresários é feito principalmente através da prática e de processos Learning-by-doing e em alguns casos Learning-byInteracting. No mesmo caso anterior, o proprietário cria pequenas inovações em seu processo de produção construindo e adaptando algumas máquinas para consecução de processos produtivos exclusivos à sua empresa. Em uma experiência mostrada pelo empresário, este disse que por meio de sugestão de um de seus clientes, criou uma máquina que inseria uma pintura no solado de alguns modelos de sua coleção. Além de vender lotes completos para este cliente, este comercializou a outros e aprendeu a fazer o mesmo processo para outros modelos de coleção.

CONTRIBUIR - A contribuição interna não é bem observada nas empresas, isso já observado na qualificação dos dados anteriormente. Em algumas empresas há intenção de melhorar a relação com os funcionários a fim de tentar uma contribuição melhor em relação a disseminação de conhecimentos. Um dos entrevistados disse que é política da empresa valorizar a função dos empregados e este disse que o faz por meio de benefícios, mesmo sendo esta uma micro-empresa, que não é tão comum esse fato a empresas desse porte no arranjo. Este é o único dos proprietários entrevistados que oferecia prêmio aos trabalhadores de linha de produção por quantidade produzida e também benefícios como cesta básica entre outros. No entanto, apesar dos benefícios, não há um processo estabelecido que incentive a disseminação do conhecimento entre os funcionários de modo a resolver problemas entre eles e transformar esse processo em algo competitivo.

AVALIAR - A tarefa de avaliação do conhecimento inicia-se com a identificação pelos proprietários das principais fontes de conhecimentos nas empresas. A abordagem de identificação de capital intelectual, conhecimentos explícitos ou outras abordagens são úteis nessa avaliação. Nos casos observados, poucos foram os empresários que estavam cientes das fontes de conhecimento essenciais na sua empresa. 
Um dos exemplos encontrados foi o de uma empresa de calçados femininos que fabrica produtos de boa qualidade e alto valor agregado. A entrevistada afirmou que possui parceria com seu fornecedor de couro, onde seus representantes em muitas ocasiões procuram desenvolver variados tipos de textura e cores para os couros curtidos baseado em opiniões de clientes. Afirmou, também, que em outros casos, ela mesma pede um modelo de couro com cores e texturas de sua escolha onde os fornecedores, ao atenderem seu pedido, procuram criar outros modelos baseados em suas opiniões.

Quando indagada se ambos adquirem vantagem com esse tipo de interação, esta disse que ganha por poder lançar produtos exclusivos no mercado, o que lhe dá um bom diferencial em relação aos seus concorrentes, e do outro lado o fornecedor pode contar com a empresa para criar novos materiais. Essa relação foi considerada fator crítico de sucesso na criação de modelos exclusivos em sua empresa.

CONSTRUA e MANTENHA - O processo de construção e manutenção de conhecimentos se relaciona ao aproveitamento da sinergia que ocorre quando o conhecimento flui e é bem utilizado dentro da organização. Este também foi um dos fatores pouco avaliados, semelhantemente aos de ordem estratégica. Na explanação que foi pedida aos entrevistados, estes afirmaram que a construção do conhecimento internamente não é tão fácil pela natureza dinâmica da criação de modelos nas várias estações e tendências. O conhecimento mais básico se mantém no processo produtivo, em alguns casos criando-se micro-inovações diferenciadas e em outros os empresários investem em treinamento e qualidade para tentar manter o conhecimento dentro da organização. Nos casos estudados, há uma nítida ausência de padronização de processos internos de produção e de compras no setor como um todo. Em relação a falta de padronização de processos internos há falta de profissional qualificado para realizar essa atividade. A falta de padronização de compras de materiais nas empresas se dá pela estratégia voltada exclusivamente ao menor preço praticado por algumas empresas. De um modo geral, o processo de construção e manutenção de conhecimento dentro das empresas, é pouco visível nos casos estudados.

DESCARTAR - A falta de um reconhecimento das fontes de conhecimento nas organizações torna esse processo também fraco nas empresas estudadas. O máximo que os respondentes puderam afirmar em relação a esse processo é a relação custo benefício de manter alguns benefícios advindos do sindicato patronal. É fato compreensível visto que são poucas as organizações que conseguem identificar suas fontes de conhecimento, sejam internas ou externas. Das empresas que conseguiam identificar alguns pontos importantes de suas fontes de conhecimento estes afirmaram que suas parcerias são fatores de sucesso e que não pretendem ainda descartar a participação destes em suas atividades de negócios. 
Para configuração dos principais fatores de sucesso nas empresas, foi questionado aos proprietários na visão destes os principais fatores que estes consideravam que compunham os mais relevantes para o sucesso na utilização do conhecimento na empresa. O gráfico seguinte resume a percepção dos empresários sobre este ponto.

Figura 4 - Fatores de Sucesso para Gestão do conhecimento

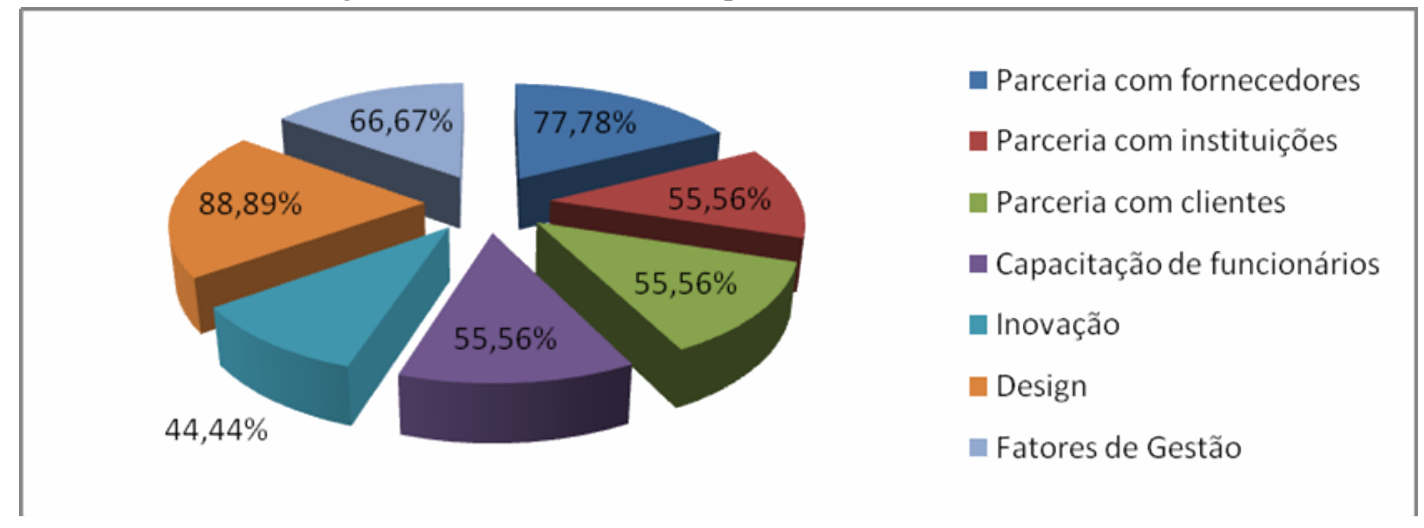

Fonte: Pesquisa de Campo

As informações mostram que as parcerias e a tarefa de design na organização são fatores considerados críticos para o sucesso das organizações, isso foi corroborado através de exemplos mostrados anteriormente. Também apóia esta afirmação o fato de que em relação a diagnóstico realizado, a atividade de aprender é a mais forte de acordo com o modelo. Deve-se considerar, entretanto, que para os casos estudados houve uma nítida divisão dos fatores percebidos como indutores de sucesso na utilização e fluência de conhecimento nas empresas. Na distribuição das empresas como mostrado nos procedimentos metodológicos, a figura um - Distribuição das empresas em relação ao número de funcionários - mostra que há três empresas que foram as maiores dos casos estudados. Exatamente para estas, os fatores de sucesso foram diferentes das demais, focando suas percepções em questões de parceria com fornecedores por meio de comprar por menores preços e fatores de gestão, geralmente relacionados a melhoria na produção, de forma a fabricar mais produtos.

O enfoque de sua competência se relaciona grandemente com os custos e produção em escala, relegando a um plano inferior os elementos relacionados ao aproveitamento do capital humano ou mesmo inexistindo em uma destas empresas a atividade de design. Um dos empresários afirmou que simplesmente copia modelos onde ele mesmo desenha ou alguns funcionários que trabalham na modelagem. Por trabalhar com escala de produção - onde este tem uma produção mensal de aproximadamente 125.000 pares - o proprietário não pretende assumir o custo de contratação de design para sua produção. 
A pouca interação destas empresas com instituições de apoio foi outro fator observado nas entrevistas. Em uma das entrevistas, um empresário disse que não tem o "tempo necessário" para procurar serviços das instituições de apoio que, embora tenha considerado estas como importantes, não se utiliza das vantagens de sua associação. Nestas três maiores empresas, todos disseram que o principal problema na sua ótica, era a incompatibilidade das ofertas de financiamentos no setor em relação a realidade das empresas. Os financiamentos são mais direcionados aos micro-empresários e poucas são as ações voltadas a financiar empresas pequenas e médias empresas que requerem um fluxo de caixa e de investimentos num aporte mais robusto.

A seção dos resultados procurou mostrar na visão do modelo proposto, os principais processos de conhecimentos realizados nos casos empresariais estudados. Para uma maior fidelização das informações, experiências, exemplos e questionamentos de ordem qualitativa foram inseridos nos argumentos como forma de tentar ao máximo identificar os processos de conhecimento, mesmo que fossem por ações não intencionais, geralmente próprios das atividades de conhecimento. As considerações abordarão argumentos finais bem como algumas possíveis ações necessárias a aproveitar melhor o conhecimento na organização.

\section{Considerações Finais}

Mediante as várias abordagens apresentadas nos últimos anos em relação à Gestão do Conhecimento nas empresas pode-se seguramente considerar que grandes são seus benefícios na atual perspectiva de inovação, de modo que inserir novos padrões de qualidade, funcionalidade em seus produtos, é fator primordial para a organização que não deseja ficar fora do mercado ou à deriva entre seus concorrentes.

O trabalho se valeu uma das abordagens utilizadas na gestão do conhecimento que se preocupa com o processo gerencial de coordenação para fazer o conhecimento fluir na empresa, bem como fortalecer os pontos de alavancagem deste na organização. Mesmo tendo como objeto de estudo empresas de calçados, ou seja, de setores tradicionais de produção, estas estão inseridas em um mercado mutável e dinâmico, em que sua permanência e desenvolvimento depende a cada dia de fatores de sucesso que sejam relacionados a Gestão do conhecimento interno para promoção de inovações. 
De forma sucinta, as nove empresas que formaram o estudo de caso múltiplo utilizam o conhecimento mais visivelmente no seu nível operacional e tático. A inexistência de fatores que corroborem a utilização de conhecimentos de modo estratégico foi visto nos dados coletados bem como nos diversos exemplos e experiências mostrado pelos empresários. Mesmo nos níveis organizacionais em que a gestão do conhecimento foi utilizada pelas organizações, estes o faziam de modo desestruturado e com pouco foco na criação de processos para resolução de problemas e disseminação das informações.

Em casos observados algumas empresas inseriam pequenas inovações em seus processos, ou mesmo mantinham relações de pareceria para desenvolvimento de produtos, que foram os casos que mais se aproximaram de uma atividade estruturada de criação e aproveitamento do conhecimento como atividade estratégica.

Para os fatores de sucesso encontrados, observou-se que as empresas que logram seus lucros por meio de escala de produção são as que menos se interessam em fatores competitivos de conhecimento de caráter mais dinâmico. Parcerias com instituições, fornecedores e foco na atividade de design são alguns dos fatores de sucesso permeados pelos proprietários como essenciais as suas atividades.

A figuração dos maiores índices de processos de conhecimentos estarem localizado na área tática e não estratégica já denota uma deficiência nos na utilização do conhecimento como ativo importante para os empresários. Em uma primeira visão, a padronização de processos que possam inserir a capacidade de gerir conhecimento nas empresas é um dos pontos que poderiam gerar maior disseminação de informações nas organizações. Agregar metas específicas para aproveitar melhor os serviços fornecidos por instituições especializadas é outra ação que pode influenciar no curso das atividades das empresas. As micro-empresas do caso foram as que mais mostraram dinamicidade em suas atividades se adaptando melhor à demanda de mercados mais exigentes e lucrativos, como foi o exemplo de empresas que exportam para diversos países da América latina e Europa.

Direcionar esforços para melhoria de processos de gestão é outro fator relevante para o setor. Em muitos dos fatores de sucesso e nas experiências foi muito falado elementos que tem relação com serviços das instituições e da atividade de design como fator competitivo. Uma gestão eficaz, no entanto, deve ser também uma meta a ser atingida, principalmente para criar mais elementos competitivos relacionados a gestão do conhecimento como inovação nos produtos ou processos, melhoria da qualidade e outros fatores de sucesso que incidem diretamente na competitividade das organizações.

\section{Abstract}


The construction of knowledge in business longer option and takes effect as an important administrative role for organizations that want to remain competitive in today's market. After the fad, the focus of the activities of knowledge today is its effective management through actions promptly to structure models for Knowledge Management. The Model Knowledge of Management Diagnostic (KMD) proposed by Bukowitz and Williams (2002) seeks to operate in this direction, which identifies weaknesses in the structure of a model of knowledge management business and propose ways to improve the dissemination and use of knowledge tactical and strategic way. Through multi-case study, this article presents the results of semi-structured interviews in nine major companies located in Footwear Production Arrangement in Campina Grande and on the model of KMD, shows how to structure the use of knowledge in organizations and also identifies practices associated with the generation of knowledge in enterprises through the experience of managers. The results suggest that companies do not have an ideal structure to use knowledge in their activities and the few cases of practices associated with the use of the knowledge focus their management in tactical levels settling actions of the strategic level, which may adversely affect the competitiveness of organization.

Keywords: Knowledge Management, process, diagnostic.

\section{REFERÊNCIAS}

ALBUQUERQUE, M. Trabalho monográfico sobre o setor coureiro de Campina Grande, Monografia da UEPB, disponível em http://www.terravista.pt/meco/3447/ Campina Grande/Pb 1998.

BARCLAY, R. U. e MURRAY, P. What is Knowledge Management. In: A Knowledge Praxis. 1997

BUKOWitZ, W. R., WILliaMS, R. L., Manual de Gestão do Conhecimento, Porto Alegre, Bookman Editora, 2002.

CASSIOLATO, J. E.; SZAPIRO, M. Aglomerações geográficas e sistemas produtivos e de inovação. Rio de Janeiro. IE/UFRJ, 2002.

COSTA, A. B. da; FLIGESNPAN, F. B. Avaliação do movimento de relocalização industrial de empresas de calçados do Vale dos Sinos. Mimeo, Porto Alegre, SEBRAE, 1997.

EDVINSON, L. MALONE, M. Intelectual Capital: Realizing your company's true value by finding its Hidden Brainpower. New York: HarperCollins, 1997

FURlanetTO, E. L., SILVA, R. J. A., Análise nas Relações nas Cadeias de Suprimento das Empresas do Arranjo Calçadista de Campina Grande. Relatório Final de Iniciação Científica - PIBIC, UFCG, Campina Grande - PB. 2006

FURlanetto, E. L., SIlVA, R. J. A., APL de Calçados de Campina Grande: Análise das Relações Entre Seus Agentes. In: XI Seminário de Gestão Tecnológica - ALTEC - Salvador, Brasil. 2005

HANSEN, M. T et al. What is your strategy for managing knowledge? Harvard Business Review, Mar./Apr., p. 106-116, 1999. 
LEONARD-BARTON, Dorothy. Nascentes do Saber: Criando e Sustentando as fontes de Inovação, Rio de Janeiro, Editora FGV, 1998.

NONAKA, I., TAKEUCHI, H. Criação de conhecimento na empresa: Como as empresas japonesas geram a dinâmica da inovação, Rio de Janeiro: $4^{\text {a }}$ Ed. Editora Campus, 1997.

PINHANEZ, M. Training and social Liaisons: Long-Lasting Industrialization in Northeast Brazil's shoe industry. Firt year doctoral research paper. International Development and Regional Planning Group - Department of Urban Studies and Planning - Massachusetts Institute of Technology, Cambridge, MA, May, 1998

POLANYI, M. The Tacit Dimension. Londres: Routledge \& Kegan Paul, 1967

SVEIBY, K. E., A Nova Riqueza das Organizações, Rio de Janeiro, Editora Campus, 1998

VON KROGH, G.; ICHIJO, K.; NONAKA, I. Facilitando a criação do conhecimento: reinventando a empresa com o poder da inovação contínua. Rio de Janeiro: Campus, 2001.

WIIG, K.M. Knowledge Management Foundations: thinking about-how people and organizations create, represent, and use knowledge. Arlington, Texas: Schema Press, 1993.

YIN, R.K. Estudo de caso: planejamento e métodos. 3 ed. Porto Alegre: Bookman, 2005.

\section{Dados dos Autores}

Nome completo: Ricardo Jorge Araújo Silva

Filiação institucional: Universidade Federal de Pernambuco

Departamento: Programa de Pós-Graduação em Engenharia de Produção

Função ou cargo ocupado: Aluno de Mestrado Acadêmico

Endereço completo para correspondência: Rua Gogóias, 06. Bodocongó. Campina Grande - PB. CEP: $58432-812$

Telefones para contato: (83) 9113-2500

e-mail:araujomail@gmail.com

Nome completo: Abraham Benzaquen Sicsú

Filiação institucional: Universidade Federal de Pernambuco

Departamento: Programa de Pós-Graduação em Engenharia de Produção 
Função ou cargo ocupado: Professor adjunto

Endereço completo para correspondência: Rua Acadêmico Hélio Ramos, s/n Cidade Universitária, Recife-PE, CEP: 50.740-530

Telefones para contato: (81) 2126.8728

e-mail:sicsu@fundaj.org.br

Nome completo: Antônio Pires Crisóstomo

Filiação institucional: Universidade Federal de Pernambuco

Departamento: Programa de Pós-Graduação em Engenharia de Produção

Função ou cargo ocupado: Aluno Doutorado

Endereço completo para correspondência: Rua Acadêmico Hélio Ramos, s/n Cidade Universitária, Recife-PE, CEP: 50.740-530

Telefones para contato: (81) 2126.8728

e-mail:apcrisostomo@hotmail.com

Recebido para publicação em: 21/09/2009

Aceito para publicação em: 04/11/2009 